\title{
O DEBATE RECENTE SOBRE AS POLÍTICAS PÚBLICAS: o caso da intersetorialidade
} numa perspectiva compreensiva

\author{
Rafael Nicolau Carvalho \\ Universidade Federal da Paraíba (UFPB) \\ Patrícia Barreto Cavalcanti \\ Universidade Federal da Paraíba (UFPB)
}

O DEBATE RECENTE SOBRE AS POLÍTICAS PÚBLICAS: o caso da intersetorialidade numa perspectiva compreensiva. Resumo: O objetivo do artigo é analisar a estratégia da Intersetorialidade a partir da contribuição da sociologia compreensiva; definir o atual estágio de discussão sobre o tema. Como metodologia, usa a pesquisa bibliográfica, tendo em vista que a mesma é largamente utilizada nos estudos exploratórios e descritivos, quando o objeto de analise é pouco estudado, dificultando o levantamento de hipóteses ou de novas interfaces. O texto está organizado em uma introdução, que faz um levantamento sobre os pressupostos das políticas públicas, e duas seções: a primeira, "o debate sobre a Intersetorialidade", mapeia o surgimento da temática, os principais conceitos, modelos analíticos e tipologias. A segunda, "contribuição da sociologia compreensiva: pensando o problema", discute as possibilidades de "aplicação" da metodologia compreensiva para analisar alguns aspectos sobre a temática, que podem contribuir com um modelo de análise de políticas públicas.

Palavras-chave: Políticas públicas, intersetorialidade, sociologia.

THE RECENT DEBATE ABOUT PUBLIC POLICIES: the case of Intersectoral comprehensive perspective.

Abstract: The article's goal is to analyze the strategy of intersectoral approach from the contribution of comprehensive sociology; set the current stage of discussion on the topic. As methodology, it uses the bibliographical research, bearing in mind that the same is widely used in exploratory and descriptive studies, when the object of analysis is understudied, making difficult the lifting of hypotheses or new interfaces. The text is organized into an introduction which makes a survey about the assumptions of public policies, and two sections: in the first "the debate on the Intersectoral approach", It maps the emergence of the theme, the core concepts, analytical models and types. In the second session, "contribution of comprehensive Sociology: thinking the problem", discuss the possibilities of "application" of the comprehensive methodology to analyze some aspects on the subject, that can contribute with a model of public policies analysis.

Key words: Public policy, intersectoral approach, sociology. 


\section{INTRODUÇÃo}

O tema políticas públicas ${ }^{1}$ tem se tornado relevante nas ultimas décadas por se propor a descrever, analisar e compreender os processos relativos à formulação, gestão e implementação de uma agenda de ações estatais para com a sociedade. Assim, proliferam modelos, métodos e estratégias de análise destas políticas compondo o que chamamos de uma área de conhecimento ou subárea no campo da ciência política, das ciências sociais, e humanas. O fato é que proliferam trabalhos, teses, dissertações sobre a temática nas mais diversificadas abordagens compondo um verdadeiro caleidoscópio de leituras sobre o tema a partir da "consolidação" da área como campo de pesquisa em inúmeros programas de pós-graduações nos mais diferentes campos do saber (HOCHMAN, 2007; SOUZA, 2006; FARIA, 2003).

Tradicionalmente, as políticas púbicas são pensadas basicamente por três abordagens distintas $^{2}$ : 1) compreende a política como processo do próprio sistema político fundado no debate clássico sobre o papel do estado; da sociedade e do governante; 2) compreende a política como processo de formação e tomada de decisão ligada aos processos entre Estado e Sociedade; 3) a partir dos anos 50 procura a definição conceptual do que seja política pública e a constituição do conceito como unidade de análise ${ }^{3}$.

No Brasil, ${ }^{4}$ mais especificamente a partir da Constituição de 1988, quando foram estabelecidos vários direitos sociais e a responsabilidade do Estado na provisão destes direitos por meio das políticas públicas, tem se ampliado o debate e o número de pesquisas empíricas sobre essa relação complexa que evidencia a tensão entre Estado e Sociedade na luta, provisão e manutenção das diferentes políticas sociais ${ }^{5}$. Sobre esta relação entre atores estatais e da sociedade civil é que alguns estudos têm se dedicado com mais ênfase aos rebatimentos desta tensão no próprio processo de implantação das políticas que, a priori, seria endógeno.

Deste modo, questionam-se os tradicionais modelos de explicação das políticas publicas que muitas vezes não evidenciam a complexidade do fenômeno, a multiplicidade de atores e suas interações com a política na vida cotidiana, bem como o aparecimento e extinção das políticas. ${ }^{6}$ Para Faria (2003, p. 21),

[...] Uma grande variedade de pesquisas empíricas e de ensaios de natureza teórico-conceitual tem demonstrado a incapacidade dos modelos tradicionais de interpretação dos mecanismos de intermediação de interesses, como o pluralismo, o corporativismo, o marxismo, em suas várias derivações, de dar conta da diversificação e da complexificação desses processos, muitas vezes marcados por interações não hierárquicas e por um baixo grau de formalização no intercâmbio de recursos e informações, bem como pela participação de novos atores [...] como, por exemplo, organizações não governamentais de atuação transnacional e redes de especialistas.

A partir da perspectiva do autor, diferentes modelos teóricos- conceituais têm se mostrado incapazes de interpretar este processo; a nosso ver, cada um articula conceitos distintos pertencentes a uma teoria específica e muitas vezes descartando outros aspectos do processo, tendo em vista sua complexidade. Destaca-se que boa parte das análises sobre as políticas publicas privilegiam uma abordagem marxista, "em suas várias derivações". Observa-se esta leitura na própria definição de políticas públicas por articular categorias marxistas como "luta de classes", "conflito", "relação entre estrutura e superestrutura", e pelo consenso entre vários autores marxistas de que as políticas públicas são um fenômeno contemporâneo na ordem capitalista burguesa. Obviamente o tema "políticas públicas" não foi objeto dos estudos de Marx, no entanto, sua análise da sociedade capitalista burguesa lançou as bases para se construir um corpo teórico sobre a economia e sociedade que estão presentes nas definições do conceito de política pública.

A partir de longos anos de estudo, Marx se dedicou à análise da sociedade burguesa com o objetivo de descobrir sua estrutura e seu funcionamento. Sua análise se inicia na segunda metade dos 1840 num longo processo de elaboração teórica no qual exprimia uma "maquinaria conceitual", descrevendo a relação homem natureza, o processo de produção, valorização e distribuição do capital bem como constituía seu método de análise. Ao longo de 15 anos formula com precisão os elementos centrais de seu pensamento que aparece no prefácio a Contribuição à critica da economia política, posteriormente nos Manuscritos econômicos filosóficos que por sua vez viabilizou sua análise em O Capital (GIANNOTTI, 2010; MANDEL, 1978).

Obviamente não cabe aqui uma análise sobre a teoria marxiana, mas apenas evidenciar como o pensamento marxista tem influenciado e determinado inúmeras análises no campo das políticas públicas de tal modo que é consenso em alguns teóricos da área situar o entendimento das análises das políticas como processo e resultado das relações complexas e contraditórias entre Estado e Sociedade, no âmbito do conflito e da luta de classes que envolvem o processo de produção e reprodução do capitalismo com intuito de demonstrar seus limites e possibilidades na produção do bem-estar nas sociedades capitalistas (BERING; BOSCHETTE, 2007; MISHRA, 1995).

Como já sinalizado, o tema não foi objeto de estudo de Marx, no entanto ao analisar as primeiras 
legislações fabris no segundo capitulo d'O Capital aponta a importância destas legislações ao impor limites ao capital e uma vitória da economia política do trabalho (MARX, 1984). O capítulo que trata da jornada de trabalho e da legislação fabril é o substrato marxiano mais importante sobre o tema e revelou seu aspecto contraditório e impotência diante da superação da ordem burguesa (BERING; BOSCHETTE, 2007). Tal análise se reproduz em muitas leituras e estudos sobre as políticas públicas trazendo esse viés.

Deste modo, fica claro que a análise, sob este enfoque, considera elementos do arcabouço teórico marxista para explicar o surgimento e desenvolvimento das políticas públicas, a natureza do capitalismo e seu grau de desenvolvimento; o papel do Estado na regulamentação das políticas públicas e o papel das classes sociais. Portanto, não se pode, nesta direção, explicar as políticas públicas sem articular o conflito entre capital trabalho e/ou Estado e classes sociais. Assim, o tema em pauta situa-se entre política e economia e entre Estado e sociedade.

Apesar da multiplicidade de estudos sobre a temática com abordagens teóricas distintas, é visível a influência das análises marxistas na conceituação das políticas públicas, mesmo na dualidade que ora expressa um mecanismo estatal de controle dos atores sociais ou como estratégia política contraditória e complexa por carregar elementos políticos e econômicos, expondo o conflito entre classes. O elemento "conflito entre as classes" parece ser um dado norteador destas definições.

Notadamente, como já sinalizado, há uma variedade de estudos que apontam a participação de outros atores sociais no processo de constituição das políticas, tendo como objetivo compreender o sentido destes processos políticos para os sujeitos que deles participam como elemento preponderante nas análises que se edificam sob este lastro teórico.

Essa perspectiva, compreensiva, é a marca de um autor que é referência nas ciências sociais e de forte influência no pensamento social contemporâneo: Max Weber. Em suas análises, tanto do ponto de vista metodológico quanto dos estudos econômicos que empreendeu dando ênfase aos aspectos culturais e religiosos, realiza uma aproximação destes processos sociais a partir das intencionalidades e ações dos sujeitos com o intuito de compreender seus efeitos, sobrepondose aos estudos de natureza puramente objetiva das condições econômicas. Desta feita, a apreensão weberiana está ligada a capturar os sentidos da ação humana; segundo o autor, "[...] conhecer um fenômeno social seria extrair o conteúdo simbólico da ação ou ações que o configuram e não apenas o aspecto exterior dessas mesmas ações." (WEBER, 1991). Assim, sua preocupação recai na compressão das ações sociais diferentemente de outras abordagens que se preocupam em explicar os fenômenos sociais com algo exterior ao indivíduo.

Ainda para o autor, só a partir do estudo de uma multiplicidade de casos e a criação de modelos empíricos de análises é possível estabelecer comparações e compreender o sentido presente nas ações revelando suas ambiguidades. Para empreender este processo Weber propôs a metodologia do tipo ideal, de valor heurístico, mas que constitui um valor cultural e intencional para pesquisador (subjetivo). Assim, a partir do tipo ideal se estabelecem comparações nos mais variados casos, de modo a compreender os traços comuns e estabelecer o tipo ideal puro como modelo explicativo daquelas ações, permitindo situar os fenômenos sociais em sua relatividade. Desse modo, entende-se por tipo ideal um sistema compreensivo de conceitos que permite formular hipóteses que explicam o desenvolvimento dos fenômenos sociais.

O exemplo mais claro em que Weber utilizou seu método foram os trabalhos sobre a sociologia das religiões, mais especificamente a Ética Protestante e o Espírito do Capitalismo, que defende a ideia que o desenvolvimento do capitalismo não seria possível nas sociedades modernas sem o elemento cultural propiciado pela Reforma protestante, especificamente, pelas doutrinas/seitas reformadas metodismo, luteranismo e com destaque para o calvinismo com o racionalismo econômico e ascese ao trabalho. Nesta perspectiva, o autor não considera o capitalismo como produto meramente das relações econômicas de produção, mas como consequência de um processo religioso e cultural moldando o ethos do capitalismo ou espírito do capitalismo. Todavia, compreende que outros elementos podem estar envolvidos no desenvolvimento do capitalismo, inclusive os de ordem econômica, pois faz parte de sua própria percepção multicausal dos fatos sociais, mas que, optou-se intencionalmente analisar o conjunto destes aspectos que são apresentados em seu texto.

Para Collins (2009, p. 79), a ética protestante e o espírito do capitalismo parecem colocar Marx de ponta cabeça, como explica,

Enquanto Marx considerava a religião como ideologia que refletia as classes econômicas, Weber parecia mostrar que o próprio capitalismo não havia sido produzido por forças econômicas, mas pela influência de ideias religiosas: a dedicação dos puritanos ao trabalho diminuía sua ansiedade em relação a sua salvação o que, segundo a doutrina teológica da predestinação não era algo garantido a todos.

No mesmo texto weber aponta ainda na introdução e em todo o primeiro capitulo a construção sistemática dos conceitos (tipo ideal) por análises dos sistemas culturais de diversas religiões/seitas para apenas ao final da obra definir o "espírito do 
capitalismo". Ainda, para Collins (2009), Weber, no mesmo período, mas em outro ensaio, argumentou que o método básico das ciências humanas não consistia em descrever os processos sociais a partir de leis abstratas, mas sim, mergulhar no ponto de vista subjetivo dos atores sociais, de modo a perceber o mundo por suas lentes e compreender suas motivações para dada ação.

É nesse ponto que a contribuição de Weber nos interessa para o tema em tela, ou seja, a sua influência no debate sobre as políticas publicas e seus métodos de análise. Assim, a perspectiva metodológica apresentada tem desenvolvido estudos que implicam a constituição de "tipos ideais" e estabelecido estudos comparados entre padrões de proteção sociais, deixando evidente os padrões econômicos e políticos também presentes (BEHRING; BOSCHETTI, 2007). No entanto, apesar destes estudos, nos interessa a partir da metodologia proposta por Weber compreender os sentidos das ações e efeitos das políticas públicas nos diversos atores envolvidos em seu processo, seja nas decisões políticas (que envolvem por si só diferentes atores), nas adesões de profissionais aos mecanismos metodológicos de operacionalização das políticas ou mesmo no sentido delas pala população usuária de seus serviços. Estes estudos têm sido tomados paralelamente com os estudos de ordem econômica na macroestrutura política.

A exposição em curso tenta destacar as diferentes contribuições dos sistemas conceituais propostos por dois clássicos das ciências sociais na discussão das políticas públicas. Contudo, é sabido que no atual estágio de desenvolvimento do campo do conhecimento das políticas públicas, este se constitui muitas vezes a partir de diferentes modelagens, métodos e técnicas próprios sobre seus processos. Para Souza (2006), o campo do conhecimento delimitado pelas políticas públicas é multidisciplinar, mas pode, também, ser considerado "holístico", pois comporta diferentes abordagens propostas por várias áreas do conhecimento como a sociologia, economia, administração, antropologia, planejamento e gestão sem muitos conflitos por comporem modelos. No entanto, como já apontado, prevalece à compreensão que ação das políticas públicas repercutem na economia e na sociedade, daí qualquer "teoria de política pública" precisa explicar as inter-relações entre Estado, política, economia e sociedade. Portanto, o interesse de pesquisadores de diferentes áreas partilhando interesse e construindo para avanços de modelos teóricos e empíricos.

\section{O DEBATE SOBRE A INTERSETORIALIDADE}

Discutir o surgimento do termo "Intersetorialidade", bem como do seu significado, é uma atividade complexa, tendo em vista que existem muitas abordagens sobre o tema, evidenciando a própria característica multidisciplinar do campo das políticas públicas. Encontram-se leituras consensuais sobre o termo, situando-o como processo de gestão das políticas públicas de modo geral e das de corte social; e dissensos, quanto à sua eficiência enquanto mecanismo racionalizador das ações no corpo destas políticas. Contudo, sobre a etimologia do termo, Dantas (2012, p. 21) nos esclarece,

O termo Intersetorialidade é indicado na literatura como possuidor de vários sentidos. Numa perspectiva mais nuclear "Intersetorialidade" deriva da junção da expressão/prefixo inter agregada a um conjunto de setores, que ao se aproximarem e interagirem entre sí podem produzir ações e saberes mais integrais e totalizantes. O prefixo inter é oriundo do latim inter que significa "no interior de dois"; "entre"; "no espaço de"; "posição intermediária", assim a palavra intersetorialidade desvela: 1) Relações entre dois ou mais setores; 2) Que é comum a dois ou mais setores.

Neste sentido, observa-se que o termo "setor", na base da compreensão do sentido de Intersetorialidade, remete às políticas públicas sociais e seus respectivos processos de gestão. Busca-se interligar diferentes políticas públicas por meio da aproximação ou "união" de seus setores de modo a combinar o efeito de suas ações. Aproximações que passam a ser pensadas a partir do debate sobre a Intersetorialidade, desde os processos decisórios, planejamento e implementação das políticas públicas pelo Estado.

Sobre o intenso processo de setorialização, Junqueira (2004) afirma que cada política pública desenvolve a seu modo uma solução, sem necessariamente considerar o cidadão ou os cidadãos envolvidos na sua totalidade, e também não considera a ação das outras políticas públicas sociais. Segundo Junqueira, Inojosa e Komatsu (1997, p. 22),

As estruturas setorializadas tendem a tratar o cidadão e seus problemas de forma fragmentada, com serviços executados solitariamente, embora as ações se dirijam à mesma criança, à mesma família, ao mesmo trabalhador e ocorra no mesmo espaço territorial e meio ambiente.

Corroborando com as ideias esboçadas pelos autores, Andrade (2006, p. 54), em seu estudo sobre a Intersetorialidade na gestão dos municípios de Fortaleza e Curitiba, explica esta contradição exposta nas ações setoriais, 
[...] nas experiências estudadas evidenciam uma inquietação no interior do Estado sobre como trabalhar com a intersetorialidade. Observou-se que em relação a ela há um consenso discursivo e um dissenso prático. Esse dissenso nasce da contradição entre a necessidade de integração de práticas e saberes requeridos pela complexidade da realidade e um aparato de Estado setorializado, onde se acumulam, com maior ou menos conflito, poderes disciplinares que estruturaram hegemonicamente sua organização. Esta organização condicionou os avanços na intersetorialidade das reformas estudadas.

Estes autores nos mostram que este modelo dividido por setores promove ações de caráter isolado, se caracterizando assim como ineficaz, já que a inclusão social passa pela satisfação de um conjunto de direitos inter-relacionados. Percebe-se também que muitas vezes, a fragmentação dessas políticas são percebidas e vivenciadas pelos profissionais que prestam diretamente os serviços à população.

Observa-se, também, que a setorização das políticas públicas é, em grande parte, influenciada pela própria segmentação das disciplinas. É como se o aparato governamental fosse todo fatiado por conhecimento "[...] ninguém encara as pessoas e famílias como totalidade que são." (INOJOSA, 2001, p. 103).

Diante do exposto, é do atual quadro de fragmentação da ação estatal, a partir da desarticulação das ações de diferentes políticas públicas e da pulverização dos direitos sociais, constituindo novas políticas setorizadas e focalizadas em um problema social específico, que emerge a discussão em torno da Intersetorialidade como uma estratégia que surge para superar a fragmentação e fragilidade das políticas sociais, com vistas a combater as iniquidades sociais. Trazem também a ideia de que possibilita uma visão integral das necessidades sociais, de forma a compreender e considerar o cidadão em sua plenitude.

Desse modo, a construção do conhecimento acerca da inter-relação da Intersetorialidade e as políticas públicas tem se mostrado profícua, notadamente nas áreas da administração pública e da saúde coletiva, como bem expressam Junqueira (1998), Inojosa (1998), Andrade (2004) e Ferreira e Silva (2005).

Além disso, a Intersetorialidade, no debate atual, vem como uma recorrente estratégia para obtenção de uma maior interlocução entre as políticas públicas, ensejando, no campo social, uma importante "ferramenta" para superação da setorialização das demandas sociais. Segundo argumenta Inojosa (2001), ela implica na conexão de saberes e experiências no sentido de dar densidade ao planejamento, monitoramento e avaliação das políticas, planos e projetos em direção a um resultado sinérgico, ao tempo em que impõe uma nova dinâmica no aparato estatal.

É importante sinalizar que a Intersetorialidade vem sendo articulada não só ao trato da constituição dos saberes aliada à reflexão sobre os processos interdisciplinares. Constata-se que seu uso percorre, atualmente, desde as agendas político-partidárias, promovendo análises sobre a prática profissional de diferentes profissionais, particularmente no contexto de planejamento e gestão das políticas públicas. Ademais, tem sido uma estratégia recorrente em algumas propostas de políticas para as cidades no âmbito do desenvolvimento urbano e social (Antropologia e urbanismo) e do projeto de Cidades Saudáveis no campo da saúde. Sua utilização nessas experiências insurge como tentativa de superar as contradições inerentes ao modelo injusto de desenvolvimento que, no caso brasileiro, vem produzindo simultaneamente um aumento da exclusão social e um desmonte gradativo dos princípios constitucionais.

A partir deste panorama, se constata que esse aparato setorial que amolda as políticas públicas, implementa políticas endógenas, ou seja, sempre de dentro para fora, atendendo à realidade de modo desarticulado, onde cada setor desenvolve as suas próprias soluções, num movimento de si para si.

Diante do levantamento bibliográfico realizado, observa-se que os estudos dos anos 1990 se dedicaram à definição de modelos intersetoriais em nível da gestão das políticas públicas dentro do aparato estatal. Nas produções recentes, diante da variedade de modelos de gestão intersetoriais, há um esforço em analisar o resultado das ações das políticas nas condições objetivas de vida das populações usuárias de seus serviços, de modo a perceber um resultado sinérgico. Todavia, outra questão que se esboça é que para além dos resultados das ações para os indivíduos, há uma preocupação em perceber como os profissionais que trabalham no aparato estatal das políticas acionam e viabilizam esta estratégia em seu cotidiano. Tendo em vista, como já mencionado, que muitas políticas já disponibilizam em diversas etapas de suas implementações arranjos intersetoriais preconizados em suas legislações, documentos, portarias etc. No entanto, como já sinalizava Andrade (2006), há um consenso teórico, e, portanto, político-estratégico, mas um dissenso prático na operacionalização deste mecanismo de gestão diluído agora num conjunto de práticas, processos organizativos, fluxos de serviços que são conduzidos por diferentes agentes. Se na literatura sobre a temática é evidente uma polissemia do termo, na prática ela também se evidencia mostrando inúmeras dificuldades dos agentes profissionais compreenderem, executarem, desenvolverem ações, experiências e movimentos intersetoriais. 
Portanto, não é apenas a integração de políticas, por meio dos seus diversos setores, mas sim na integração de diversos sujeitos sociais, com suas motivações, visão de mundo, formação profissional, subjetividades e aspectos culturais também em jogo que interferem nesta relação. Desvenda-se um "novo" horizonte analítico nas leituras sobre as políticas públicas por meio da estratégia da Intersetorialidade a partir desta perspectiva.

O que se constata é que se cristalizaram "modelos intersetoriais" no planejamento, na gestão e na execução das políticas públicas, sem perceber que a simples constituição destes modelos (com suas regras e leis) não é garantia de efetivação de suas diretrizes; há um componente importante que tem sido deixado de lado nas análises destas questões, ou seja, os agentes profissionais que são incumbidos de executarem estes modelos.

Portanto, a "ação intersetorial" não se esgota no âmbito da gestão ou da organização dos serviços ou de uma política especifica, mas na articulação de várias organizações públicas, de conhecimentos, pessoas e seus modos de compreensão sobre o processo. Esta mudança de concepção tem implicado mudança nos conhecimentos teóricosmetodológicos de vários atores sociais implicados neste processo, como gestores, técnicos e profissionais. O "sucesso" desta estratégia está, também, relacionado à participação e à posição que cada indivíduo ocupa em sua operacionalização, dos elementos simbólicos que os mobilizam e os interesses que os conduzem neste processo.

\section{CONTRIBUIÇÃO DA SOCIOLOGIA COMPREENSIVA: pensando o problema}

A partir das leituras realizadas evidenciase uma polissemia para o termo que, a nosso ver, constitui-se um conjunto de modelos que tentam capturar os "modos de fazer" dos agentes profissionais às tipologias empregadas. Assim, partindo-se do conceito, embora impreciso, da Intersetorialidade, desenham-se metodologias em sua aplicação, as quais sintetizamos nas tipologias a seguir:

1) Modelo de gestão: a Intersetorialidade, enquanto conceito, está presente nas agendas políticas partidárias, nos discursos dos formuladores de políticas publicas de diferentes áreas que tentam trabalhar em conjunto, nos documentos oficias de várias políticas que apresentam e definem 0 conceito, criando uma agenda de trabalho compartilhada de responsabilidade técnica, gerencial e financeira;

2) Modelo Técnico-político: criam-se grupos de discussões, câmaras técnicas, Fóruns de gestores, grupos de trabalho que preservam a composição de diferentes setores e áreas de conhecimento de modo a proteger o caráter intersetorial e interdisciplinar;

3) Modelo Estratégico-profissional: espera-se uma incorporação dos modelos anteriores nas ações profissionais dos agentes envolvidos na execução das políticas, como: grupos de discussão nos serviços, criação de fluxos e rotinas de trabalho integrado, criação de parcerias entre profissionais de diferentes políticas, criação de protocolos, modelos integrados de avaliação.

Para dar suporte a estes modelos, diversas políticas têm adotado o principio da territorialidade e da matricialidade social como forma de dispor seus serviços em uma rede organizada e hierarquizada compondo as redes socioassistenciais nos territórios das políticas públicas de corte social.

A existência desses modelos não garante a aplicabilidade da Intersetorialidade, de modo que o grande desafio na gestão das políticas públicas, mencionado em diversos estudos debatidos em conferências e fóruns, é a falta de articulação entre as políticas, tanto na execução de suas ações quanto nos efeitos destas na vida dos usuários dos serviços públicos. A esse respeito, cita-se Inojosa (2001, p. 102),

O aparato governamental preocupase com cada uma de suas fatias e seus produtos, isoladamente. Dificilmente conseguimos perceber, nos vários níveis de governo, a prática de avaliação de resultados. Faz-se a avaliação dos produtos oferecidos: quantas consultas foram realizadas, quantas cestas básicas estão sendo distribuídas, quais as obras terminadas. Mas de fato que diferença isso faz para o grupo que vive em tal região, com tal perfil, para segmento ou qual, que tem determinadas características? Isso é uma coisa que não se sabe nem se pergunta.

Em recente estudo, Santos (2012) demonstra por meio de uma pesquisa realizada com os profissionais de serviços públicos de saúde no município de Cabedelo- PB, que os mesmos se apropriam do conceito de Intersetorialidade presente na literatura sobre a temática no campo da saúde em seus discursos, mas não sabem descrever e/ou elencar, com clareza, ações que eles considerem como intersetoriais. Os arranjos apresentados pelos profissionais, que os caracterizam como atividades pontuais, mostram-se superficiais e frágeis.

Cavalcanti et al (2011) ressaltam em estudo com profissionais de duas políticas públicas (saúde 
e criança adolescente) no município de João Pessoa - PB, que há um arranjo intersetorial do ponto de vista de gestão nas duas políticas, mas um distanciamento do cumprimento dos princípios que regulam 0 atendimento dos adolescentes pelas políticas citadas. Aponta que são necessárias mudanças na condução das políticas, principalmente na articulação dos agentes profissionais; ressalta, também, que a estratégia da Intersetorialidade se revela fundamental, porém depende de um lastro de variáveis ainda não discutidas.

Por sua vez, Souza (2012), em pesquisa com gestores das políticas públicas do município de Cabedelo- $\mathrm{Pb}$, aponta que os mesmos conhecem os modelos intersetoriais de gestão e afirmam implementá-los, no entanto atribuem a responsabilidade aos profissionais na execução das ações. Conclui afirmando que o conhecimento sobre a Intersetorialidade poderá apontar os caminhos a serem experimentados no planejamento e na construção de uma estratégia de gestão ligada aos processos dos agentes profissionais.

Portanto, se cada modelo existe com suas "leis e regras", o que impede a difusão da estratégia da Intersetorialidade entre os agentes profissionais?

Fica evidente que a estratégia da Intersetorialidade se coloca no campo da prática a partir da adesão de diferentes profissionais às atividades desempenhadas no conjunto dos processos de gestão das políticas públicas. Uma abordagem sociológica do problema busca compreender como os profissionais interpretam, compreendem e executam a Intersetorialidade em seu cotidiano, visto que, como já citado anteriormente, os estudos em curso têm se concentrado em analisar esse processo no âmbito da gestão das políticas, desprezando, assim, as abordagens de caráter qualitativo, no sentido de resgatar o significado presente nos fatos através do modo como os sujeitos sociais a vivenciam.

Debruçar-se sobre esse tema como objeto sociológico é, antes de tudo, descrever as condições em que são produzidos os discursos, sobre as experiências e vivências da Intersetorialidade no cotidiano desses agentes, ou seja, analisar os processos através dos quais são produzidos os "fatos" e que como os discursos contribuem para legitimar os processos analisados. Aanálise proposta vem romper com as abordagens "tradicionais" do campo das políticas públicas e da administração. Essas abordagens têm priorizado análises que não levam em conta o significado presente nos fatos, nos resultados e no impacto das políticas públicas na vida dos sujeitos às quais se destinam.

Daí, salienta-se a contribuição desta leitura tomando como aporte teórico o sistema conceitual proposto por Weber que define que, na medida em que não é possível explicar todas as relações causais em torno de um fenômeno social, escolhemse alguns elementos do quais se possa partir e que se julgue importante analisar. Deste modo, não se pretende explicar todos os processos relacionados à análise e gestão das políticas públicas, mas sim compreender um processo singular dotado de significados que carecem de interpretação.

Para elaborar este modelo interpretativo, parte-se dos conceitos delimitados na literatura sobre o tema, que por meio desta compreensão assume a postura de "tipos ideias", no entanto, como já exposto, estes modelos se resumem a regras e leis que se propõem a explicar a Intersetorialidade como algo "externo" aos agentes, de modo a quantificar suas ocorrências e regularidades. Assim, salienta-se que a construção desta nova abordagem poderá levar à feitura de novo tipo ideal sobre a ação intersetorial, que a nosso ver, tem importantes componentes culturais e simbólicos pertencentes a um grupo social especifico.

Portanto, vale salientar que esta abordagem não descarta outras leituras possíveis sobre o tema, pelo contrário, parte deste constructo para construir outras possibilidades neste campo teórico, tendo em vista que os estudos sobre os processos de gestão têm dado visibilidade aos problemas estruturais relativos a tais políticas, como por exemplo, as formas de financiamento, os modelos de gestão seguidos, os diversos modos de organização dos processos de trabalho, parâmetros legais e a própria estrutura de rede que as políticas encontram para se materializarem.

No entanto, destaca-se a sua importância ao inferir que a busca pela compreensão, o resgate dos significados sobre estes modelos de gestão, as práticas sociais que eles engendram, é uma forma do conjunto das ciências sociais contribuírem para a ampliação das abordagens, na construção de uma prática ampliada entre os profissionais que levem em conta esse conjunto de significados.

Assim, torna-se necessário realizar estudos que não se limitem a fetichizar o tema intersetorial, mas sim provocar o debate, arrolando estas categorias que estão intrinsecamente vinculadas à implementação e, portanto, gestão de tais políticas.

\section{CONCLUSÃO}

O artigo buscou discutir a "estratégia da Intersetorialidade" a partir do mapeamento dos conceitos na literatura sobre a temática tentando integrar alguns elementos: 1) a constituição de uma área do conhecimento - a própria política pública 2) a contribuição de duas tradições sociológicas para compreender seus aspectos políticos, sociais, culturaise econômicos; 3 )o desvelamento dos setores onde se movimentam os agentes profissionais que decidem, desenham e implementam as políticas públicas; 4) a perspectiva de compressão proposta a partir destes elementos às tipologias sobre a Intersetorialidade levantada.

O principal foco analítico foi delimitar o arcabouço teórico diante da pluralidade de 
abordagens no campo das políticas públicas e a temática da intersetorialdiade como objeto. Corrobora-se, portanto, com o pensamento de Reis (2003) que aponta que o cientista social que se dedica ao tema das políticas públicas tem que delimitar com clareza a perspectiva teórica do seu trabalho, sabendo do debate travado com outras posições e a compreensão de alternativas metodológicas diferentes. A necessidade dos pesquisadores em explicitar os pressupostos teóricos que sustentam suas analises seria uma condição para promover um debate mais "frutífero" no campo das políticas públicas sem disputa ou concorrência entre os modelos teóricos, como sustenta Souza (2006).

Portanto, o artigo tem a intenção de oferecer uma leitura tendo como horizonte a sociologia compreensiva para os estudos sobre o aspecto destacado neste trabalho, no que alude à compreensão do sentido sobre a Intersetorialidade e sobre os agentes profissionais que a executam.

Apesar desta abordagem ser apenas um opção metodológica entre várias outras, destaca-se como positivo o caráter multidisciplinar deste campo do saber que hoje oferece muitos "instrumentos" para analisar diferentes temáticas dentro do campo das políticas públicas.

Portanto, tem-se o entendimento que os modelos, as teorias e perspectivas descritas neste artigo vão continuar coexistindo e permitindo uma compreensão de diversos problemas que permeiam o campo das políticas públicas como suas agendas políticas, seus conflitos, papel dos atores sociais, setores e instituições envolvidos nos mais diferentes processos de gestão de modo a ofertar um amplo leque de possibilidades que tentem dar conta da complexidade dos fenômenos sociais; todas válidas e importantes.

\section{REFERÊNCIAS}

ANDRADE. L. O. M. de. A saúde e o dilema da intersetorialidade. 2004. Tese (Doutorado em Ciências Médicas) - Faculdade de Ciências Médicas, Universidade Estadual de Caminpas, Campinas, 2004.

BEHRING, Elaine; BOSCHETTI, Ivanete. Política social: fundamentos e história. São Paulo: Cortez, 2006. cap. 2-3. (Biblioteca Básica de Serviço Social).

BOSCHETTI, Ivanete et al (Org.). Política social no capitalismo: tendências contemporâneas. São Paulo: Cortez, 2008.

CAVALCANTI, P. B; DANTAS, A. C. S; CARVALHO, R. $\mathrm{N}$. Contornos e sinergias entre a política de saúde e o adolescente privado de liberdade: intersetorialidade como desafio. Textos \& Contextos, Porto Alegre, v. 10, n. 2, p. 399 - 410, ago./dez. 2011.
COLLINS, R. Quatro tradições sociológicas. Petropolis: Vozes, 2009.

FARIA, Carlos Aurélio Pimenta de. Idéias, conhecimentos e Politicas Públicas: um inventario sucinto das principais vertentes analíticas recentes. Revista Brasileira de Ciencias Sociais, São Paulo, v. 18, n. 51 , fev. 2003.

GIANNOTTI, J.A. Novos Conceitos, Velhos Rumos. In:_. Certa herança marxista. Rio de Janerio: Boblioteca Virtual de Ciencias Humanas, 2010.

HOCHMAN, Gilberto; ARRETCHE, Marta; MARQUES, Eduardo. Politicas públicas no Brasil. Rio de Janeiro: Fiocruz, 2007.

INOJOSA, Rose Marie. Intersetorialidade e a configuração de um novo paradigma organizacional. Revista de Administração Pública, Rio de janeiro, v. 32, n. 2, p. 35-48, mar./abr. 1998.

Sinergia em políticas e serviços públicos: desenvolvimento social com Intersetorialidade. Cadernos FUNDAP, São Paulo, n. 22, p. 102-110, 2001.

JUNQUEIRA L. A.; INOJOSA, R. M.; KOMATSU, S. A gestão da intersetorial das políticas sociais e o terceiro setor. Saúde e Sociedade, São Paulo, v. 13, n. 1, p. 25-36, 2004.

Descentralização e intersetorialidade: na gestão pública municipal no Brasil: a experiência de Fortaleza. In: CONCURSO DE ENSAYOS DEL CLAD, 11, 1997, Caracas. EI tránsito de la cultura burocrática al modelo de la gerencia pública: perspectivas, posibilidades y limitaciones. Caracas: UNESCO/CLAD, 1998.

Prates. Novas formas de gestão na saúde: descentralização e intersetorialidade. Saúde e Sociedade, São Paulo, v. 6, n. 2, p. 31-46, 1997.

LIMA, T.C. MIOTTO, R.C. Procedimentos metodológicos na construção do conhecimento: a pesquisa bibliográfica. Revista Katálysis, Florianópolis, v. 10, n. esp., p. 37-45, 2007.

MACHADO, Lurdes A. Construindo a intersetorialidade. [200-?]. Disponível em:<portalses.saude.sc.gov.br>. Acesso em: 21 jun. 2011.

MANDEL, E. O capitalismo tardio. São Paulo: Unicamp, 1990.

MARX, K. Introdução à critica da economia politica. São Paulo: Martins fontes, 2003. 
Legislação fabril: cláusulas sanitárias e educacionais e sua generalização na Inglaterra. In: O capital. São Paulo: Abril, 1982.

O capital: critica da economia politica. São Paulo: Nova Cultural, 1988.

MISHRA, R. O Estado providencia na sociedade capitalista: politicas públicas na Europa, América do Norte e Austrália. Portugal: Celta, 1995.

MOURA, P.G.M. Bolsa Família: projeto social ou marketing político? Revista Katálysis, Florianópolis, v.10, n.1, p. 115-122, jan./ jun. 2007.

NASCIMENTO, Sueli do. Reflexões sobre a intersetorialidade entre as políticas públicas. Serviço Social e Sociedade, São Paulo, n. 101, p. 95-120, jan./mar. 2010.

PEREIRA, P.A. Discussões conceituais sobre política social como política pública e direito de cidadania. In: BOSCHETTI, Ivanete et al (Org). Política social no capitalismo: tendências contemporâneas. São Paulo: Cortez, 2008.

SANTOS, J.R.C. Rede psicossocial e o desafio da intersetorialidade: concepções e práticas dos profissionais de cabedelo-pb. Trabalho de Conclusão de Curso (Especialização em Gestão em Saúde) Secrataria de Educação a Distancia, Universidade Estadual da Paraíba, João Pessoa, 2012.

SOUZA, Celina. Politicas Pública: uma revisão da literatura. Revista Sociologias, Porto Alegre, n. 16, p. 20-45, 2006.

M. M. Reforma psiquiátrica, rede psicossocial e o desafio da Intersetorialidade. Trabalho de Conclusão de Curso (Especialização em Gestão em Saúde) - Secrataria de Educação a Distancia, Universidade Estadual da Paraíba, João Pessoa, 2012.

SPOSATI, A. Gestão Pública intersetorial: sim ou não? - comentários de experiência. Serviço Social \& Sociedade, São Paulo, n.85, p. 133-141, mar. 2006.

WEBER, M. A ética protestante e o espirito do capitalismo. São Paulo: Companhia das letras, 2004.

\section{Conceitos sociológicos fundamentais.} In: Economia e sociedade. Brasília, DF: UNB, 1991.

Ensaios sobre a teoria das ciências sociais. São Paulo: Centauro: 2003.
Notas

Apesar da consolidação do tema como campo do saber Souza (2006) afirma que não existe uma única, nem melhor, definição sobre políticas públicas. Muitas definições enfatizam aspectos diferentes ou relacionam um conjunto de aspectos como o papel da política pública na solução de problemas, o embate de idéias e interesses, o papel dos governos, a cooperação entre governos, instituições e grupos sociais (SOUZA, 2006, p. 68-69).

2 Para Frey (2000), estas abordagens referemse ao campo da Ciência Política que constitui posteriormente o campo das Políticas Públicas. Classificação semelhante é apresentada por Pereira (2009). Souza (2006) também adota este modelo explicativo da constituição do campo das Políticas Públicas dedicando a descrevê-los em seu texto.

3 Sobre esta perspectiva Frey (2000, p. 214) esclarece: "Nos Estados Unidos, essa vertente de pesquisa da ciência política começou a se instituir já no início dos anos 50, sob o rótulo de 'policy Science', ao passo que na Europa, particularmente na Alemanha, a preocupação com determinados campos de políticas só toma força a partir do início dos anos 70 , quando com a ascensão da socialdemocracia o planejamento e as políticas setoriais foram estendidos significativamente. Já no Brasil, estudos sobre políticas públicas foram realizados só recentemente. Nesses estudos, ainda esporádicos, deu-se ênfase ou à análise das estruturas e instituições ou à caracterização dos processos de negociação das políticas setoriais específicas."

4 Moura (2007) aponta que diferentemente dos EUA o debate em torno das políticas publicas no Brasil vai se consolidar em torno das políticas sociais, no papel do Estado em sua provisão ora centralizador, descentralizado e regulador.

5 Para Souza (2006) apesar das políticas publicas e das políticas sociais constituírem um mesmo campo existem distinções importantes nos estudos sobre as políticas publicas e políticas sociais. Ainda para autora estudos sobre políticas publicas buscam explicar a natureza da política analisada e seus processos. Os primeiros estudos sobre política social dedicavam-se analisa o Estado de bem estar Social e provisão dos direitos sociais. Tais estudos vêm da tradição européia do que da norte-americana e tem sido bastante desenvolvida no Brasil. No entanto, Pereira (2009) não faz distinção entre os segmentos afirma que: "política social é um gênero particular de política pública", conclui-se que as políticas possuem os mesmo processos de gestão. Neste artigo trata-se das políticas sociais como política pública.

6 Para Pereira (2009), alguns estudos sobre as políticas públicas tentam dar conta deste processo de surgimento, desenvolvimento e extinção de algumas políticas sociais a partir de fatores históricos conjunturais. 


\section{Rafael Nicolau Carvalho}

Assistente Social

Doutor em Sociologia pela Universidade Federal da

Paraíba (UFPB)

Pesquisador do Setor de Estudos e Pesquisas em Saúde e Serviço Social e Professor Assistente do Departamento de Serviço Social da Universidade Federal da Paraíba (UFPB)

E-mail: rafaelcg_carvalho@yahoo.com.br

\section{Patrícia Barreto Cavalcanti}

Assistente Social

Doutora em Serviço Social (PUC/SP)

Coordenadora do Setor de Estudos e Pesquisas em Saúde e Serviço Social e Professora Associada III do Departamento de Serviço Social a Universidade Federal da Paraíba (UFPB)

E-mail: patriciabcaval@gmail.com

\section{Universidade Federal da Paraíba (UFPB)}

Cidade Universitária - João Pessoa - PB - Brasil

CEP: $58051-900$ 